\title{
Efficiency of Individual Prophylaxis of Dental Caries Using Dental Gel Ispring Based on Ganoderma Lutsidum in Schoolchildren in Tashkent
}

\author{
Abilov P.M ${ }^{*}$ \\ Graduate student of the Department of Pediatric Dentistry of the Tashkent State Stomatological Institute \\ *Corresponding author: Abilov P.M, Graduate student of the Department of Pediatric Dentistry of the Tashkent State Stomato- \\ logical Institute; Tel: 317-278-6210; E-mail: pulatabilov1985@maiil.ru
}

Received Date: September 24, 2018; Accepted Date: November 30, 2018; Published Date: November 03, 2018

Citation: Abilov P.M (2018) Efficiency of Individual Prophylaxis of Dental Caries Using Dental Gel Ispring Based on Ganoderma Lutsidum in Schoolchildren in Tashkent. J Dent Oral Health 5: 1-4.

\section{Abstract}

This article presents the results of preventive measures for the application of the dental gel and Spring on the basis of Ganoderma Lutsidum. In his studies, the author used this gel in the treatment of acute herpetic stomatitis and published data in the journal Sci-article (2017, No. 10) and in the treatment of chronic catarrhal gingivitis (Journal of Pediatrics, Uzbekistan No. 1, 2018). In this study, the author suggests an oral prophylaxis of the oral cavity using a gel based on Ganoderma Lutsidum. In materials and methods, this gel is compared with known toothpastes, such as Colgate, Bland-a-Med. The results show the high caries resistance of children using the dental gel ISpring.

\section{Clinical Significance}

The individual course of prophylaxis developed by us with the help of a unique gel based on the Ganoderma Lutsidum will increase the results of individual programs, in particular, to reduce the growth of caries by $2-2.5$ times, the growth of the caries in 2-2.3 times.

\section{Relevance}

The need to implement effective programs for the prevention of dental caries is dictated by its high prevalence and intensity. In Tashkent, the prevalence and intensity of dental caries significantly exceed the average indicators of the Global Data Bank for Europe [2-4, 9].

In Uzbekistan, the prevalence of caries according to prof. O.S. Yuldoshkhonova (2015) in 3-7year old varies from 16 to $82 \%$, and the average intensity is 4.1 . Those. every 3 children almost all teeth are affected by tooth decay, which is certainly due to extremely low level of oral hygiene. Moreover, among the children of adolescence, the prevalence and intensity of caries fluctuates at the level of $92 \%$, and in some regions, and $100 \%$, which of course depends on the ecological state, low concentration of fluorides in drinking water, training of medical personnel in medical institutions, and much more [1].

As we know, the main goal of individual prevention of dental diseases is the improvement of the entire country,

(C)2018 The Authors. Published by the JScholar under the terms of the Creative Commons Attribution License http://creativecommons.org/licenses/by/3.0/, which loize.marechal@umontreal.ca

maximilien.laviolette-brassard@umontreal.ca through the improvement of the prevention system in the regions.

Hygienic procedures are the basis of preventive programs introduced in schools, kindergartens, boarding schools, etc. Knowledge and ability to use the right toothbrush, paste, flosses makes it possible to turn an individual hygienic procedure into an effective preventive program, where every child knows about the benefits of daily brushing of teeth a way to avoid infectious and inflammatory diseases of the maxillofacial region. It is important to create a program "Individual hygiene of caries prevention", which will include all indications for the use of toothbrushes, pastes and flosses so that the child correctly uses them and for their intended purpose [6-8].

In this regard, I would like to note the dental gel iSpring from the company "Gano Exel", which has 15 certificates of conformity, including GMP, Halal, FDA, ISO and much more. The products have no analogues to date. In this regard, I would like to demonstrate the possibilities of individual hygiene with the help of products of the company "Gano Exel" on the example of schoolchildren in the Mirabad district of Tashkent $[5,10]$.

\section{Purpose of the study}

To increase the effectiveness of individual dental caries prophylaxis in adolescent children by the example of school \# 263 of the Mirabad district and compare the results with traditional means of individual hygiene. 


\section{Materials and methods of research}

To implement the tasks at the Department of Otorhinolaryngology, Children's Otorhinolaryngology and Dentistry of the Tashkent Pediatric Medical Institute, 652 schoolchildren aged 7 to 16 years old, No.263 of the school were examined. All schoolchildren were divided into 3 groups: 1 group (main) - 376 schoolchildren, individual prevention was carried out with iSpring dental gel, 2 group (comparisons) 197 schoolchildren, individual hygiene was carried out using standard personal care products (Colgate tooth paste, Blenda-med), 3rd group (control) - 79 schoolchildren who did not perform individual hygiene.

iSpring dental gel has an anticariogenic effect due to the presence of polyglucans and triterpenes. The gel is recommended to apply 2 times a day, for 3 months. results were compared with traditional treatments.

Methods of examination included: clinical (collection of anamnesis, examination of the oral cavity, determination of CSR (C-caries, S-seale, R-remote) indices, CPITN (need for treatment of periodontal disease), determination of the hygienic state of the oral cavity according to Green Vermilion and statistical (using the Matna-Whitney test).

Parents of all children gave their written consent to participate in the experiment.

\section{Results of the study}

The clinical examination made it possible to trace the regularities occurring in the surface layers of the enamel after the treatment and prophylactic measures and to make a com- parative evaluation of the effectiveness of the iSpring dental gel using the Ganoderma Lutsidum in a removable and permanent bite. Thanks to the introduction of the 4 -stage principle of clinical examination of caries-susceptible patients into the practice of pediatric dentistry, it became possible to achieve our goal.

Stage 1 - dispensary selection, identification of caries-susceptible children

Stage 2 - dispensary records, records of sick children subject to dispensary.

Stage 3 - dispensary observation, treatment and prophylactic measures and monitoring of their effectiveness

Stage 4 - withdrawal from the medical examination - longterm follow-up of the effectiveness of dispanerization and in case of a decrease in the CSR + cs index, the CSR is withdrawn from the dispensary observation

As a result of individual preventive measures, the hygienic state of the oral cavity of the 1 group of sick children was significantly improved, compared to the comparison group and the control group (diagram 1).

After 1 year, the most significant changes occurred in the main group, after carrying out individual preventive measures using dental gel iSpring based on Ganoderma Lutsidum. In the comparison group, the indices slightly improved, but 113 poor schoolchildren had poor hygiene, 37 in poor. In the control group where no individual prophylaxis was performed, everything remained at the same level.

In the main group, the results achievede in a year of individual caries prevention with iSpring gel are stabilized with good and satisfactory oral hygiene.

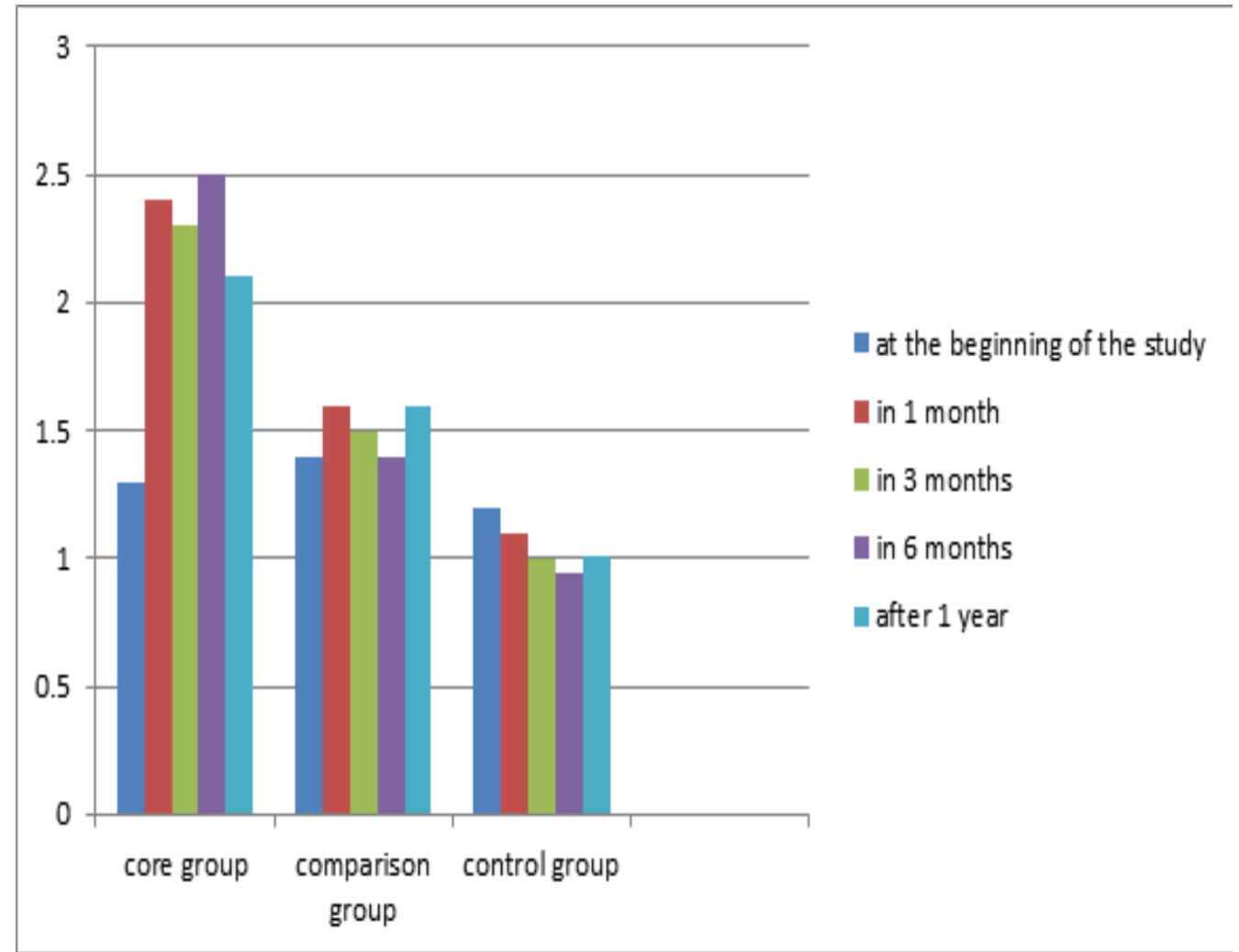

Diagram 1. Monitoring the effectiveness of therapeutic and prophylactic measures in the main, control and comparison groups. 


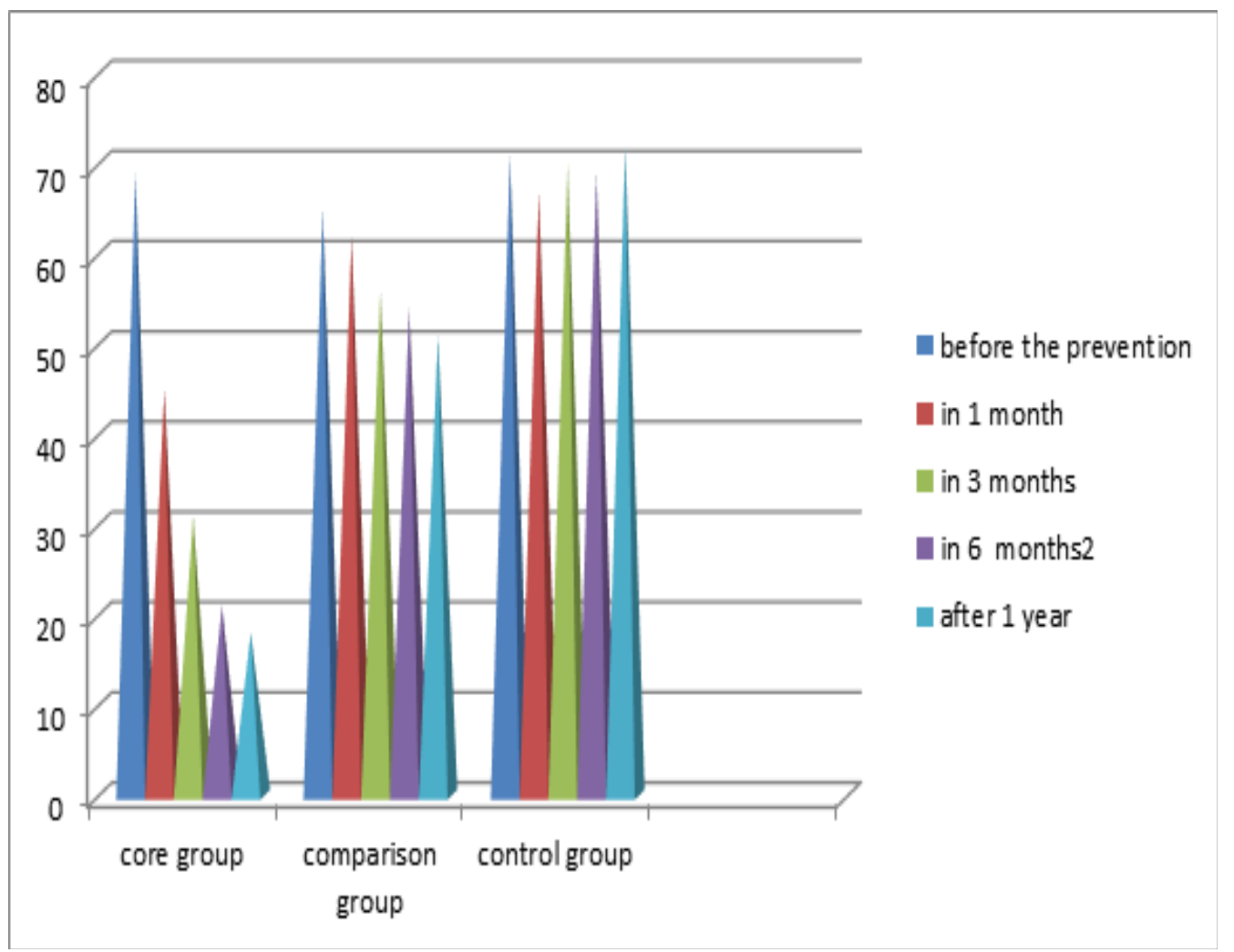

Diagram 2. Dynamics of need for treatment of periodontal diseases against the background of preventive measures with dental gel iSpring in comparison with toothpaste Colgate, Blend-a-Med.

Defining the CPITN index in the main group, the need for periodontal treatment already after 3 months becomes lower than the comparison and control groups. There is a decrease in the need for treatment of periodontal diseases by 3.1 times. Patients in the comparison group showed only minor improvements, whereas in the control group, no signs of improvement were seen at all (figure 2).

In the main group, the need for treatment of periodontal disease significantly decreased and for 1 year kept at the same level, whereas in the comparison group, the neediness changed slightly, and in the control group it remained practically unchanged.

Evaluation of the effectiveness of individual preventive measures was carried out by the CSR+CS and CSR indices. The data are given in Table 1.

\section{The conclusion}

1. Reduction of the prevalence increase in the main group is 4 times less than in the comparison group and control group. In the comparison group, the increase in caries was 10.4 times

2. The developed method of individual prevention with dental gel iSpring allows to achieve high results in the implementation of individual programs: the intensity of caries decreased by $92.5 \%$, the prevalence of caries by $81.7 \%$.

3. Individual preventive measures should be carried out in a comprehensive manner, including individual and professional oral hygiene with an individual selection of hygiene products to neutralize the oral fluid, controlled tooth cleaning. lessons of hygiene for the development of motivated forms of oral care.

\begin{tabular}{|l|l|l|l|l|l|l|}
\hline Group & $\begin{array}{l}\text { Before the } \\
\text { study }\end{array}$ & in 3 months & $\begin{array}{l}\text { in } \\
\text { months }\end{array}$ & after 1 year & Growth of caries & $\begin{array}{l}\text { Effectiveness of } \\
\text { prevention }\end{array}$ \\
\hline Main group & 13,85 & 14,08 & 14,96 & 15,73 & 0,21 & $90,02 \%$ \\
\hline $\begin{array}{l}\text { Comparison } \\
\text { group }\end{array}$ & 13,97 & 16,67 & 17,84 & 18,92 & 2,04 & $87,83 \%$ \\
\hline control & 13,76 & 17,83 & 18,34 & 19,05 & 20,86 & $82,45 \%$ \\
\hline
\end{tabular}

Table 1. Dynamics of the level of caries intensity at the stages of the study according to the data of the CSR index and CSR+cs 
Discussion: After analyzing the effectiveness of the application of the dental gel on the basis of Ganoderma Lucidum, it can be stated with certainty that the iSpring gel is an effective remedy in the fight against caries, which supports the research data and numerous publications in the PUBMED and Web of the Science.

Thanks: I express my deep gratitude to the Tashkent State Stomatological Institute and the GANO excel company in the person of Laziza Askarova for assistance in research and in the right direction along the research path.

\section{Reference}

1) Abilov P.M (2017) Perfection of methods of diagnostics and treatment of acute herpetic stomatitis in children. Scarticle, International WAC-Journal, Moscow 10:18-25

2) Abilov P.M, Makhkamova F.T (2018) Clinical and functional evaluation of the effectiveness of treatment of chronic catarrhal gingivitis in children with the use of biologically active additives based on Ganoderma Lutsidum. Pediatrics, Scientific and Practical Journal, Tashkent 1: 108-111.

3) Attin T, Hickcl R (2001) Statement by the DGZMK / DGZ Bleaching of discolored teeth 72-73.

4) Berger A (2003) ln-Office-Bleaching unter Verwendungeiner Plasmalampc. Fallbeispiele zur Aufhellung vitaler und avilaler Zahne/A. Berger Qintessenz 7:765 -772.

5) Boh B, Berovic M, Zhang J, Zhi-Bin L (2007) Ganoderma lucidum and its pharmaceutically active compounds. Biotechnol Annu Rev 13: 265-301.

6) Blunk Uwe (2004) Behandlung sensibler Zahnhalse. ZP international 8: 616-620.

7) onecker M (2003) Trends in dental caries in Latin American and Caribbean 5-6 and 11-13 years aid children: a systematic review. M. Bonecker Community Dent Oral Epidemiol 31: 152-157.

8) Carvalho C. K (2003) Microbiological asassment of saliva from children subsequent to atraumatic restorative treatment (ART) C.K. Carvalho Int. J. Pediatr. Dent 13: 186192.

9) Doc. MU Dr. Ivo Drizhal, CSc (2001) Modern ideas about plaque Doc. MU Dr. Ivo Drizhal. 23-38.

10) Wachtel-Galor S, Tomlinson B, Benzie IF (2004) Ganoderma lucidum ("Lingzhi"), a Chinese medicinal mushroom: biomarker responses in a controlled human supplementation study. Br J Nutr 91:263-269.

\footnotetext{
Submit your manuscript to a JScholar journal and benefit from:

g Convenient online submission

- Rigorous peer review

- Immediate publication on acceptance

- Open access: articles freely available online

9 High visibility within the field

- Better discount for your subsequent articles Submit your manuscript at http://www.jscholaronline.org/submit-manuscript.php
} 